vol.6. No.1 - 2019

\title{
THE EFFECTIVENESS OF ORAL SUCROSE IN MANAGING INFANTS' PAIN DURING IMMUNIZATION Gad R F ${ }^{1}$, Abusaad FE ${ }^{2}$, Dowling $\mathrm{DA}^{3}$, Bassiouny MR ${ }^{4}$, Abd El Aziz MA ${ }^{5}$. \\ ${ }^{1}$ Faculty of Nursing, Mansoura University \\ ${ }^{2}$ Faculty of Nursing, Mansoura University \\ ${ }^{3}$ Frances Payne Bolton School of Nursing, Case Western Reserve University \\ ${ }^{4}$ Faculty of Medicine, Mansoura University \\ ${ }^{5}$ Faculty of Nursing, Mansoura University \\ Email of the corresponding author: drrashafawzy@ mans.edu.eg
}

\begin{abstract}
Treating pain during vaccination should be a part of pediatric primary health care around the world, as untreated pain in children has short and long-term consequences. Few studies of pharmacologic and non-pharmacologic methods of pain relief during immunization have been conducted in low-and-middle-income countries. Finding a cheap and effective pain intervention would improve primary health care. The current study aimed to evaluate the effectiveness of oral sucrose as a method of pain management during immunization among infants through six months of age. A randomized controlled experimental design was used. The study sample included 80 infants distributed into sucrose and control groups. Data were collected in an Egyptian primary health center. Outcome measures, including pain, as measured by the FLACC pain scale, crying time, and heart rate, were measured at three time points (before, during, and after injection). There were statistically significant differences during and after immunization $(\mathrm{p}<.001)$ reflecting lower: scores of pain, crying duration, and rising in heart rate for the sucrose group compared to the control group. The study supports the effectiveness of oral sucrose in managing infants' immunization pain and recommends for providing clinical setting with safe resources and education for proper administration of oral sucrose in pain management.
\end{abstract}

Keywords: Immunization, Oral sucrose, pain management

\section{Background and Significance}

Immunization is considered an essential component of primary health care as a preventive health measure that occurs frequently in childhood. Immunization produces immune-resistance to infectious diseases and it saves up to 3 million children each year (1). Intramuscular injection is the commonly route used during immunization. According to the Egyptian obligatory immunization schedule, most of injections are given during the first 6 months of life (2). Research evidence indicates that Immunization is one of the most painful procedures in infancy $(3,4)$. This causes distress for the infants, parents, and providers. The most important complication is fear of injections for infants and their parents which leads to non or incomplete -adherence to immunization schedules. Negative experiences with injections lead to the development of needle fears in some children. These consequences are sometimes neglected or inappropriately treated in the infant population (5).

To ensure infant safety and prevent long-lasting consequences related to immunization procedures, methods to manage infants' pain should be provided. Interventions for pediatric procedurerelated pain in primary care include pharmacological and non-pharmacological methods. Concerning pharmacological 
methods, analgesia is not routinely used for infants under 6 months of age during painful procedures such as immunization, heel lance, and venipuncture (6). Although topical anesthetic [EMLA] such as lidocaine and prilocaine have been proved to be effective in decreasing vaccination needle-related pain in various studies, it has to be applied for 20 to 60 minutes before painful procedure according to which commercial preparation is being used. This preapplication time is not always available especially in a busy clinical area like vaccination clinics (7). Other pharmacological methods like vapocoolant sprays and ethyl chloride which not only provide immediate onset of action and approximately 20 seconds of dermal and epidermal anesthetic duration but also produce unpleasant anxious cold sensation particularly in children who perceive it as a painful sensation (8). Delayed onset of action, cost, and inconvenience of Pharmacological methods have resulted in outweighing of non-pharmacological ones regarding acute pain management (9).

Non-pharmacological methods have been shown to be effective, costless, and convenient in reducing procedurerelated pain. Administration of sweettasting solutions, mainly sucrose, has been found to have a pain relieving effect in both term and pre-term newborns(10). Releasing an endogenous opioid activated by the sweet taste is the mechanism in which oral sucrose reduces pain, (11). There are a large number of studies and evidence demonstrating analgesic effects of sweet solution in neonatal population but, studies with older infants especially those who live in Middle Eastern countries are lacking (12).

Examining the use of nonpharmacological methods for reducing immunization pain is necessary. The aim of this study is to evaluate the effectiveness of oral sucrose in managing infants' pain during Immunization. The study addressed the hypothesis of "Oral sucrose will decrease the infants' painful experience during immunization".

\section{Methods}

2.1Study design and setting

A randomized controlled experimental study was conducted in Child Primary Health Care Center (Reayt Tefl Awal), located in Mansoura city, Dakahlia Governate, Egypt.

\subsection{Sampling}

The study population included infants aged two, four or six months who were attending the immunization clinic to undergo routine immunizations. Healthy breastfed infants who came to the clinic with their mothers are included in the sample. Infant exclusion criteria included infant unable to tolerate oral fluids, or had received paracetamol in the day prior to immunization. The sample size was determined by using a power $=.80$ and a medium effect size (.5). The total sample size was 80 infants, 40 infants in each group of the two (sucrose \& control) groups.

\subsection{Instruments}

Two instruments were used in this study. The first is the Demographic Characteristics instrument, which was developed for the purposes of the study. It includes the infant's name, ID number, gender, age, weight, pre-injection state, time since last feeding, and randomized group (A, B, or C). It was developed by the researcher and revised by pediatric nursing experts.

The FLACC scale was used to measure pain before, during, and after the immunization injection. The FLACC scale, developed by (13), measures pain based on observations in five categories: facial expression, position of legs, activity, cry, and consolability, scored 0-2 for each Total scores range from zero to ten; $0-4$ indicates mild pain, 5-6 indicates moderate 
THE EFFECTIVENESS OF ORAL SUCROSE IN MANAGING etc...

pain, while 7-10 indicates severe pain. Interrater reliability is high 0.94 (14).

Additionally, crying time and heart rate changes were measured as indirect measures of pain. The infant's crying duration in response to the needle- related procedure was measured in seconds using the android application stopwatch (G Stop) offered in Google play store (15). Crying was measured up to 2 minutes after injection.

Procedure.

After the approval of the Research Ethics Committee of Faculty of Nursing, Mansoura University, the official permission for conducting the study was obtained from Agency of Egyptian Ministry of Health and health administration office in Dakahlia Governate. The research team consisted of the researcher and three research assistants (RA) who were associate degree nurses working in the study setting.

The first RA determined if the mother met the inclusion criteria and obtained a written consent.

Eighty cards marked A or B were arranged in a small box; where the first RA nurse asked the eligible infant's mother to choose a card from the cards box that indicated the assigned group: sucrose (Group A) or control group (Group B). In the vaccination room, the second RA assisted the mothers to be seated in a chair and in holding the baby in a right-sided, cradled position then she counted the infant's heart rate for one full minute. After the researcher assessed the FLACC pain score, the second RA gave the infant $2 \mathrm{ml}$ of $[25 \%$ sucrose (A) or sterile water (B)according to the chosen card] one minute before injection.

During injection, the third RA intramuscularly injected the (DPT $+\mathrm{HBV}+\mathrm{HIB})$ vaccine in the left thigh vastuslateralis muscle using nonpyrogenic syringe $23 \mathrm{G} \quad \mathrm{X} \quad 1$ " and 0.6 X $25 \mathrm{~mm}$ needle. The researcher measured infant's crying time in response to injection up to 2 minutes then she assessed the FLACC pain score.

After injection, the researcher reassessed the FLACC pain score while the second RA counted the infant's heart rate for one full minute.

The timing of the interventions before injection was based on the determination of a systematic review (16) that found that to be effective sweet solutions used for infants beyond the neonatal period needed to be given not more than one minute before the painful procedure for sustainability of the analgesic effect. After finishing the study session, the RA gave the infant the oral polio vaccine to complete the infant's required vaccinations.

\section{Data collection}

Data collection was carried out weekly over 7 weeks in the spring season of 2015 . The number of participants ranged from 15-20 every day. Each infant spent 4 to 6 minutes in the vaccination room.

\section{Statistical analysis}

Data were analyzed with SPSS version 21. Discrete data were described using number and percent. Association between categorical variables was tested using Chisquare test. Data of the study were meeting the criteria of parametric data using Shapiro-Wilk Test of Normality. Continuous variables were presented as mean \pm SD (standard deviation) and compared with Student t test. All statistical tests were done at fixed values significance $(\mathrm{p} \leq .05)$.

\section{Results}

No statistically significant differences were found between the study groups in either infants' sex $(p=.502)$, age $(p=.845)$, weight $(p=.761)$, the time since the last feeding $(p=.239)$, or pre-intervention state $(p=.314)$. The majority of infants in the study sample were nonexclusively breastfed and were calm and awake before the injection as shown in Table 1. 
Concerning pain scores, there were no significant differences between the study groups in pain scores before injection $(p=.794)$. During and after injection, the means of pain scores in sucrose group $(5.40 \pm 1.11 \& 3.15 \pm 1.56)$ were

significantly $\quad(p<.001)$ lower when compared to control group $(9.65 \pm 0.70 \&$ $8.93 \pm 1.1)$ respectively as illustrated in Table 2.

Regarding crying time, the mean of crying time measured in seconds was significantly $(p<.001)$ lower in sucrose $(18.18 \pm 15.17)$ group compared to control group (89.18 \pm 26.56$)$ as shown in Table 3 . Change in heart rate is the difference between heart rate before and heart rate after injection. The means of change in heart rates in sucrose group was significantly lower when compared to control group $(p=.009 \quad \& p=.036)$ as illustrated in Table 4.

\section{Discussion}

Absence of statistically significant differences between the study groups in infants' characteristics proportions related to sex, age, and weight or means related to the time since the last feeding precludes any chance for these factors to influence the study outcomes particularly pain scores through perception or threshold.

Pain Scores Outcomes

The means of pain scores were measured by FLACC pain scale before, during, and after injection. The study revealed that there were no significant differences in the mean FLAAC scores between the study groups before injection. This precludes also any difference in baseline pain scores accounting for subsequent differences.

The present study demonstrated that the pain scores in sucrose group was significantly lower when compared to those in control group during and after injection as illustrated from Table 2 .

The sweet taste of the solutions (sucrose, glucose, and dextrose) induces releasing endogenous opioids that mitigates the intensity of pain experienced by infants during needle injection. In accordance with this finding, there are many studies support the effectiveness of oral sweet solution particularly sucrose in terms of reducing pain scores during different painful procedures including vaccination for either newborns (17) or infants up to 6 -12 months $(19,21)$. $75 \%$ oral sucrose reduced pain scores even for 16-19month-old infants (22).However, there were no significant difference in reducing pain scores when $33 \%$ oral sucrose (23) or $24 \%$ oral sucrose (24) were used for toddlers and young children immunization. This paradox proposes a hypothesis that higher concentrated sucrose could be more effective in managing vaccination pain for toddler and young children.

Crying Time Outcomes

The current study revealed that the crying time was significantly lower in sucrose and breastfeeding groups when compared to the control group. Regarding lower crying time in sucrose compared to control, this finding is in accordance with $(25,26)$ where sucrose was given to infants 2,4 , and 6 month 2 minutes before the injection. In contrary to the study finding, sucrose did not reduce the crying time when used to manage toddler and young children's vaccination pain (23).

Heart rate outcomes

The current study revealed that the infants' heart rates significantly increased after injection secondary to stress and pain. Infants' heart rates in sucrose groups after injection were significantly lower when compared to their peers in control group. This is similar to previous studies that demonstrated the effectiveness of sucrose regarding physiological recovery (18) were all supporting the analgesic effect of sucrose in preventing the rise in heart rate pain response for neonates and infants in different minor painful procedures. 
THE EFFECTIVENESS OF ORAL SUCROSE IN MANAGING etc...

\begin{abstract}
Limitations
Some limitations were encountered in this study, including methodological limitations inherent in the non-blinding design. There were some limitations related to data collection. Uncontrolled consolable acts considered one of the limitations where the number and the type of the used consolable acts varied between one or more of shushing, distracting words, cuddling, rocking, and upright position with rubbing back or rubbing buttocks. The third limitation regarding data collection was manual assessment of heart rate. The final limitation was that the mothers were asked to recall or estimate the time since the last feeding of their infants. This limit the accuracy of data as mothers may not remember the exact time and time estimation may differ from person to another.
\end{abstract}

\section{Conclusion}

In the current study, oral sucrose was effective in reducing the painful experience of the infant during immunization by lowering: pain scores, crying duration, and rising in heart rate. So when it is available and safe oral sucrose should be given to infants to manage their immunization related pain.

\section{Recommendations}

- Providing safe water and resources to safely make oral sucrose solution

- Well trained staff capable of constituting oral sucrose in an appropriate percentage, and recognizing safe administration.

- Educational programs for parents and staff about managing pain during immunization and how to use oral sucrose.

8. References

1. United Nations International Children's Emergency Fund [UNICEF]. United Nations International Children's Emergency Fund: immunization. [Internet]. 2017 [cited 2017 Sep 10]. Available from: http://www.unicef.org/immunization/

2. Egyptian ministry of health. Immunization schedule [Internet]. 2017 [cited 2017 May 15]. Available from:

http://www.mohp.gov.eg/EventDetails. aspx?subject_id=2331

3. Taddio A, Ipp M, Thivakaran S, Jamal A, Parikh C, Smart S, et al. Survey of the prevalence of immunization noncompliance due to needle fears in children and adults. Vaccine [Internet]. 2012;30(32):4807-12. Available from: http://dx.doi.org/10.1016/j.vaccine.201 2.05.011

4. Esfahani MS, Sheykhi S, Abdeyazdan Z, Jodakee M, Boroumandfar K. A comparative study on vaccination pain in the methods of massage therapy and mothers' breast feeding during injection of infants referring to Navabsafavi Health Care Center in Isfahan. Iran J Nurs Midwifery Res [Internet]. 2013;18(6):494-8. Available from: http://www.pubmedcentral.nih.gov/arti clerender.fcgi ?artid=3917134

5. Eden LM, Macintosh JL, Luthy K e, Beckstrand RL. Minimizing pain during childhood vaccination injections: improving adherence to vaccination schedules. 2014;127-40.

6. Shah V, Taddio A, McMurtry CM, Halperin S a., Noel M, Riddell RP, et al. Pharmacological and Combined Interventions to Reduce Vaccine Injection Pain in Children and Adults. Clin J Pain [Internet]. 2015;31(10):1. Available from: http://content.wkhealth.com/linkback/o penurl?sid=WKPTLP:landingpage \&an =00002508-900000000-99265

7. Abuelkheir M, Alsourani D, AlEyadhy A, Temsah M-H, Meo SA, Alzamil F. EMLA(R) cream: a painrelieving strategy for childhood vaccination. J Int Med Res [Internet]. 2014;42(2):329-36. Available from: 
http://www.ncbi.nlm.nih.gov/pubmed/ 24501164

8. Hogan ME, Smart S, Shah V, Taddio A. A systematic review of vapocoolants for reducing pain from venipuncture and venous cannulation in children and adults. J Emerg Med [Internet]. 2014;47(6):736-49. Available from: http://dx.doi.org/10.1016/j.jemermed.2 014.06.028

9. McGowan A, Cottrell S, Roberts R, Lankshear A. Minimising pain response during routine infant immunisation. Community Pract [Internet]. 2013;86(6):24-28 5p. Available from: http://ezproxy.library.dal.ca/login?url= http://search.ebscohost.com/login.aspx ?direct $=$ true $\& \mathrm{db}=\mathrm{c} 8 \mathrm{~h} \& \mathrm{AN}=10419978$ 2\&site=ehost-live

10. Campbell N, Cleaver K, Davies N. Oral sucrose as analgesia for neonates: How effective and safe is the sweet solution? A review of the literature. J Neonatal Nurs [Internet]. 2014;20(6):274-82. Available from: http://dx.doi.org/10.1016/j.jnn.2014.05. 008

11. Cooper S, Petty J. Promoting the use of sucrose as analgesia for procedural pain management in neonates: A review of the current literature. $\mathrm{J}$ Neonatal Nurs [Internet]. 2012;18(4):121-8. Available from: http://dx.doi.org/10.1016/j.jnn.2012.05. 003

12. Kassab MI, Roydhouse JK, Fowler C, Foureur M. The Effectiveness of Glucose in Reducing Needle-Related Procedural Pain in Infants. J Pediatr Nurs [Internet]. 2012;27(1):3-17. Available from: http://dx.doi.org/10.1016/j.pedn.2010.1 0.008

13. Merkel T.; Shayevitz, J. R.; Malviya, S. SI. V-L. The FLACC: a behavioral scale for scoring postoperative pain in young children. Pediatr Nurs [Internet]. 1997;23(3):293-7. Available from: https://www.researchgate.net/profile/T erri_VoepelLewis/publication/13998379_The_FL ACC_A_Behavioral_Scale_for_Scorin g_Postoperative_Pain_in_Young_Chil dren/links/00b7d533ab604ce90700000 0/The-FLACC-A-Behavioral-Scalefor-Scoring-Postoperative-Pain-inYoung-

14. Voepel-Lewis T, Zanotti J, Dammeyer JA, Merkel S. Reliability and validity of the face, legs, activity, cry, consolability behavioral tool in assessing acute pain in critically ill patients. Am J Crit care. 2010;19(1):55-61.

15. Useful apps. Stopwatch and timer with laps - Android Apps on Google Play [Internet]. Pleven, Bulgaria: Google play store; 2013 [cited 2013 Dec 3]. Available from: https://play.google.com/store/apps/deta ils?id=klb.timer.stopwatch.chronometr

16. Harrison D, Stevens B, Bueno M, Yamada J, Adams-Webber T, Beyene $\mathrm{J}$, et al. Efficacy of sweet solutions for analgesia in infants between 1 and 12 months of age: a systematic review. Arch Dis Child. 2010;95(6):406-13.

17. Stevens B, Yamada J, Lee GY, Ohlsson A. Sucrose for analgesia in newborn infants undergoing painful procedures. Cochrane Libr. 2013.

18. Harrison D, Larocque C, Bueno M, Stokes Y, Turner L, Hutton B, et al. Sweet Solutions to Reduce Procedural Pain in Neonates: A Meta-analysis. Pediatrics. 2017;139(1):e20160955.

19. Chen S, Zhang Q, Xie R-H, Wen SW, Harrison D. What is the Best Pain Management During Gastric Tube Insertion for Infants Aged 0-12months: A Systematic Review. J Pediatr Nurs. 2016

20. Moradi F, Imani A, Keyghobadi S, Nazari H, Ghorbani R, Keyghobadi T. 
THE EFFECTIVENESS OF ORAL SUCROSE IN MANAGING etc...

Assessment of the Effect of $20 \%$ Oral Sucrose on Pain Relief from Hepatitis B Vaccine Injection in Full Term Infants. ZUMS J [Internet]. 2012;20(79):61-8. Available from: http://zums.ac.ir/journal/article-11757-en.html

21. The Royal Childrens' Hospital Melbourne. Sucrose (oral) for procedural pain management in infants [Internet]. 2017 [cited 2017 Jan 1]. Available from: http://www.rch.org.au/rchcpg/hospital_ clinical_guideline_index/Sucrose_oral _for_procedural_pain_management_in _infants/

22. Yilmaz G, Caylan N, Oguz M, Karacan CD. Oral sucrose administration to reduce pain response during immunization in 16-19-month infants: a randomized, placebo- controlled trial. Eur J Pediatr. 2014;173(11):1527-32.

23. Harrison D, Elia S, Manias E, Royle J, others. Sucrose and lollypops to reduce immunisation pain in toddlers and young children: Two pilot randomised controlled trials. Neonatal, Paediatr Child Heal Nurs. 2014;17(1):19.

24. Harrison D, Reszel J, Barrowman N, Martelli B, Sharp D, Vailancourt R. Be sweet to toddlers during needles: pilot randomized controlled trial of sucrose compared to placebo. Nurs Reports. 2015;5(1).

25. Hatfield LA, Chang K, Bittle M, Deluca J, Polomano RC. The analgesic properties of intraoral sucrose: an integrative review. Adv Neonatal Care. 2011;11(2):83-92.

26. Kavthekar S, Patil R, Kurane A, Bharati H. Comparison of analgesic effect of $24 \%$ sucrose and breast milk in healthy infants less than 2 months of age. Int $\mathrm{J}$ Contemp Pediatr. 2016;3(4):1375-9.

27. McCall JM, DeCristofaro C, Elliott L. Oral sucrose for pain control in nonneonate infants during minor painful procedures. J Am Assoc Nurse Pract. 2013;25(5):244-52.

Table 1: Infants' Characteristics Data of the Study Groups

\begin{tabular}{|c|c|c|c|c|c|c|}
\hline \multirow{2}{*}{ Items } & \multicolumn{2}{|c|}{ Sucrose Group 40} & \multicolumn{2}{|c|}{ Control Group 40} & \multirow{2}{*}{$\begin{array}{l}\text { Test of } \\
\text { sig. }\end{array}$} & \multirow{2}{*}{$p$-value } \\
\hline & $n$ & $\%$ & $n$ & $\%$ & & \\
\hline \multicolumn{7}{|l|}{ Sex } \\
\hline Male & 19 & 47.5 & 22 & 55.0 & \multirow[t]{2}{*}{$x^{2}=.45$} & \multirow[t]{2}{*}{.502} \\
\hline Female & 21 & 52.5 & 18 & 45.0 & & \\
\hline \multicolumn{7}{|l|}{ Age in months } \\
\hline 2 month & 16 & 40.0 & 19 & 47.5 & \multirow[t]{3}{*}{$x^{2}=.336$} & \multirow[t]{3}{*}{.845} \\
\hline 4 months & 12 & 30.0 & 8 & 20.0 & & \\
\hline 6 months & 12 & 30.0 & 13 & 32.5 & & \\
\hline \multicolumn{7}{|c|}{ Type of feeding } \\
\hline Exclusive & 15 & 37.5 & 11 & 27.5 & \multirow[t]{2}{*}{$x^{2}=.912$} & \multirow[t]{2}{*}{.340} \\
\hline Nonexclusive & 25 & 62.5 & 29 & 72.5 & & \\
\hline \multicolumn{7}{|c|}{ Pre-intervention state } \\
\hline Quiet sleep & 11 & 27.5 & 7 & 17.5 & \multirow[t]{4}{*}{$x^{2}=3.56$} & \multirow[t]{4}{*}{.314} \\
\hline Calm awake & 26 & 65.0 & 26 & 65.0 & & \\
\hline Active awake & 1 & 2.5 & 5 & 12.5 & & \\
\hline Crying & 2 & 5.0 & 2 & 5.0 & & \\
\hline \multicolumn{7}{|l|}{ Infant weight } \\
\hline Mean \pm SD & \multirow{2}{*}{\multicolumn{2}{|c|}{$\begin{array}{l}7102.50 \pm 1709.62 \\
43(0)-10200\end{array}$}} & \multicolumn{2}{|c|}{$6982.50 \pm 1798.84$} & \multirow[b]{2}{*}{$t=0.306$} & \multirow[b]{2}{*}{.761} \\
\hline Min-Max & & & 400 & 1000 & & \\
\hline \multicolumn{7}{|c|}{ Time since last feeding in hours } \\
\hline Mean \pm SD & \multirow{2}{*}{\multicolumn{2}{|c|}{$\begin{array}{l}1.37 \pm 0.7 \\
0.50-2.5\end{array}$}} & \multirow{2}{*}{\multicolumn{2}{|c|}{$\begin{array}{l}1.21 \pm 0.47 \\
0.50-2\end{array}$}} & \multirow[b]{2}{*}{$t=1.19$} & \multirow{2}{*}{.239} \\
\hline Min-Max & & & & & & \\
\hline
\end{tabular}

Note. $n=$ number; $\%=$ percentile; $x^{2}=$ chi square. $t=$ student $t$ test $\quad * p<.05 . * * p<.01$. 
Gad R F et., al.

\begin{tabular}{|c|c|c|c|c|}
\hline \multirow{2}{*}{$\begin{array}{ll}\text { FLACC Pain } \\
\text { Score }\end{array}$} & Sucrose Group & Control Group & \multirow[t]{2}{*}{$t$} & \multirow[t]{2}{*}{ p-value } \\
\hline & Mean \pm SD & Mean \pm SD & & \\
\hline Before injection & $0.28 \pm 0.93$ & $0.33 \pm 0.76$ & 0.26 & .794 \\
\hline During injection & $5.40 \pm 1.11$ & $9.65 \pm 0.70$ & 20.55 & $<.001 * * *$ \\
\hline After injection & $3.15 \pm 1.56$ & $8.93 \pm 1.1$ & 19.15 & $<.001 * * *$ \\
\hline
\end{tabular}

Table 3: Infants' Crying duration in seconds

\begin{tabular}{|l|l|l|l|l|}
\hline Crying time & Sucrose Group & Control Group & $t$ & p-value \\
\hline Mean \pm SD & $18.18 \pm 15.17$ & $89.18 \pm 26.56$ & 14.68 & $\begin{array}{l}<.001 * * \\
*\end{array}$ \\
\hline Min-Max & $2-57$ & $53-120$ & & $* * * p<.001$. \\
\hline
\end{tabular}

Table 4: Change in Heart Rate

\begin{tabular}{|l|l|l|l|c|}
\hline Change in HR & Sucrose Group & Control Group & $t$ & $\mathrm{p}$-value \\
\hline Mean \pm SD & $4.70 \pm 3.24$ & $17.13 \pm 5.98$ & 11.56 & $<.001^{* * *}$ \\
\hline
\end{tabular}

